\title{
SPECTROSCOPIC AND SCATTERING INVESTIGATION OF ISOPOLY-MOLYBDATE AND TUNGSTATE SOLUTIONS
}

\author{
KA YUEN SIMON NG and ERDOGAN GULARI* \\ Department of Chemical Engineering, The University of Michigan, Ann Arbor, MI 48109, \\ U.S.A.
}

(Received 6 October 1983; accepted 21 November 1983)

\begin{abstract}
Detailed spectroscopic and scattering investigations of isopoly-molybdate and -tungstate solutions as a function of concentration and $\mathrm{pH}$ were made. From scattering results the apparent molecular weights were determined as a function of time and concentration. We find that the results agree with the aggregation scheme of simple $\rightarrow$ hepta $\rightarrow$ octa $\rightarrow\left[\mathrm{Mo}_{36} \mathrm{O}_{112}\right]^{-8} \rightarrow$ protonated polymeric species, for molybdate solutions. Tungstate solutions aggregate according to simple $\rightarrow$ Y-polytungstate $\rightarrow$ paratungstate-A $\rightarrow$ paratungstate-B $\rightarrow \Psi$-metatungstate. The molybdate solutions exhibited very rapid equilibration, but the tungstate solutions required several days to reach equilibrium. From the discrete changes in the Raman spectra of both systems we find that the formation of isopoly anions is not a continuous process and that only certain species are present in solution. Our results do not rule out the formation of significant quantities of the octamolybdate anion as suggested by previous investigators.
\end{abstract}

The isopoly-molybdates and -tungstates constitute a large class of inorganic compounds and have been the subjects of two reviews ${ }^{1,2}$ and numerous investigations. ${ }^{3-8}$ These compounds consist of a simple cation and a condensed molybdate or tungstate anion. Solutions of these compounds are the starting point for molybdate and tungstate-based supported catalysts for hydrodesulfurization and hydrodenitration. Supported molybdates and tungstates are also good candidates to become sulfur tolerant methanation and water gas shift reaction catalysts. As a part of our efforts to develop high activity, high dispersion catalysts, we investigated the formation of isopoly species in solution as a function of concentration and $\mathrm{pH}$.

The following is a brief review of the conditions for the existence of the various isopoly species studied in this work.

*Author to whom correspondence should be addressed.

\section{(a) Isopolymolybdates in solution}

Whilst there has been confusion and contradictory findings ${ }^{9}$ regarding the existence of polynuclear species such as $\mathrm{Mo}_{4} \mathrm{O}_{13}{ }^{2-}$, at present the following species appear to be generally accepted (1): $\mathrm{MoO}_{4}{ }^{2-}$ ion is the stable species above $\mathrm{pH} 6.5$; for $4.5<\mathrm{pH}<6.5$, the paramolybdate $\left(\mathrm{Mo}_{7} \mathrm{O}_{24}\right)^{6-}$ exists in equilibrium with $\mathrm{MoO}_{4}{ }^{2-}$.

$$
7\left(\mathrm{MoO}_{4}\right)^{2-}+8 \mathrm{H}^{+} \leftrightharpoons\left(\mathrm{Mo}_{7} \mathrm{O}_{24}\right)^{6-}+4 \mathrm{H}_{2} \mathrm{O} \text {. }
$$

Further acidification leads to the formation of the octamolybdate anion $\left(\mathrm{Mo}_{8} \mathrm{O}_{26}\right)^{4-}$ between pH 2.9 and 1.5. Formation of larger aggregates at lower $\mathrm{pH}$ values was initially postulated by $\mathrm{Jahr}^{10}$ but not proven. From an analysis of Raman spectra, Tytko and Schonfeld ${ }^{15}$ showed that the anion $\mathrm{Mo}_{36} \mathrm{O}_{112}{ }^{8-}$ is also present in solution below a pH of 2.0. At pH 0.9 , molybdic acid $\left(\mathrm{MoO}_{3} \cdot \mathrm{H}_{2} \mathrm{O}\right)$ precipitates from solution and redissolves with further increases in the hydrogen ion concentration. Below pH 0.9, 
positively-charged species such as $\mathrm{MoO}_{2}{ }^{+}$and $\mathrm{MoO}^{4+}, \mathrm{HMo}_{2} \mathrm{O}_{6}{ }^{4+}$ have been reported. ${ }^{11}$ In concentrated $\mathrm{HCl}$ solutions, the presence of $\mathrm{MoO}_{2} \mathrm{Cl}_{2}$ species was also deduced from the Raman spectra. ${ }^{\text {? }}$

\section{(b) Isopolytungstates in solution}

In the highly alkaline region ( $\mathrm{pH}>8$ ), the tungstate ion exists as the normal tungstate species $\mathrm{WO}_{4}{ }^{2-}$. Upon acidification to a $\mathrm{pH}$ of 5-6, the paratungstate-A ion $\left[\mathrm{HW}_{6} \mathrm{O}_{21}\right]^{5-}$ is formed by the reaction (1):

$$
6 \mathrm{WO}_{4}{ }^{2-}+7 \mathrm{H}^{+} \leftrightharpoons\left[\mathrm{HW}_{6} \mathrm{O}_{21}\right]^{3-}+3 \mathrm{H}_{2} \mathrm{O} \text {. }
$$

The paratungstate- $\mathrm{A}$ ion is in slow equilibrium with the paratungstate- $\mathrm{B}$ ion $\left[\mathrm{W}_{12} \mathrm{O}_{36}(\mathrm{OH})_{10}\right]^{10-}$.

$$
2\left[\mathrm{~W}_{6} \mathrm{O}_{20}(\mathrm{OH})\right]^{5-}+4 \mathrm{H}_{2} \mathrm{O} \leftrightharpoons\left[\mathrm{W}_{12} \mathrm{O}_{36}(\mathrm{OH})_{10}\right]^{10-} \text {. }
$$

At high concentrations, the B ion is predominant. ${ }^{12}$ Aging solutions of paratungstate ions result in the formation of $\Psi$-metatungstate $\left[\mathrm{W}_{24} \mathrm{O}_{72}(\mathrm{OH})_{12}\right]^{12-}$. Polytungstate- $Y$ has been obtained shortly after acidification of the normal tungstate solution to a $\mathrm{H}^{+}$to $\mathrm{WO}_{4}{ }^{2-}$ ratio of 2.00 and has been formulated as (5):

$$
\left[\mathrm{W}_{12} \mathrm{O}_{x}(\mathrm{OH})_{y}\right]^{-72-(2 x+y)} .
$$

When the concentration of $\mathrm{WO}_{4}{ }^{2-}$ is less than $5 \times 10^{-5} \mathrm{M}$, no isopoly anions are formed; instead, the insoluble tungstic acid $\mathrm{H}_{2} \mathrm{WO}_{4}$ is formed by direct protonation. ${ }^{13}$

\section{EXPERIMENTAL}

(a) Materials

All the solutions were prepared from certified ACS grade (Fisher) Ammonium molybdate, sodium tungstate and doubly-distilled deionized water.

\section{(b) Methods}

(1) Light scattering. Light scattering measurements were made with a laser light scattering spectrometer consisting of a $2 \mathrm{~W}$ argon-ion laser, a 64 channel multibit Malvern correlator, an HP 5300B counter, and an HP 9835 computer. All the optics were mounted on a vibration isolation table to eliminate the effect of building vibrations. Intensity measurements were made by photon counting at $90^{\circ}$ scattering angle. By using pure benzene as a reference, molecular weights were computed from the intensity measurements. Diffusion coefficients were obtained from the autocorrelation function of the scattered light using: ${ }^{14}$

$$
g(\tau)=A^{*} \exp \left(-D K^{2} \tau\right)
$$

where $g$ is the field autocorrelation function, $D$ is the diffusion coefficient, $K$ is the scattering vector $(=4 \pi n / \lambda \sin \theta / 2)$ at an angle $\theta$ with an incident light wavelength of $\lambda$, and $\tau$ is the delay time.

(2) Raman spectroscopy. Raman spectra were obtained with a SPEX Triplemate spectrograph coupled to a Tracor Northern 1024 large area intensified diode array detector. The 514.5 line of a 4W Argon ion laser was used as the excitation source. Typical power at the sample was on the order of $100 \mathrm{~mW} .5 \mathrm{~mm}$ dia. NMR tubes were used as sample cells. Since the detector simultaneously measured a $1300 \mathrm{~cm}^{-1}$ region, all the spectra were obtained without moving any of the gratings. Spectra were taken either with 2 or $4 \mathrm{~cm}^{-1}$ resolution. Typically, each spectrum consisted of 512 co-added scans taking the total time of ten minutes. Since the spectrum is totally digital and no gratings 'were moved, spectral subtraction could be used very reliably to eliminate the background without increasing the noise.

\section{RESULTS}

\section{(a) Light and $X$-ray scattering}

The results of the scattering experiments are shown in Table 1 . We emphasize that all the molecular weights and the hydrodynamic radii calculated from the diffusion coefficient using the Stokes-Einstein relationship are apparent values:

$$
D=k T / 6 \eta r \pi
$$

$D$ is the diffusion coefficient, $k$ is the Boltzmanu constant, $T$ is the absolute temperature, $\eta$ is the viscosity of the solvent, and $r$ is the hydrodynamic radius.

This is due to the fact that these values were determined using solutions of finite concentrations, and the scattering theory is rigorous only at the limit of infinite dilution. Since the degree of association is concentration dependent, the standard technique of making a Zimm plot to eliminate the concentration dependence is not possible. The apparent molecular weights of polymeric molybdates are 1260 at $\mathrm{pH} 2.6,660$ at $\mathrm{pH} 5.5$ and 260 at $\mathrm{pH} 9.0$ for a $0.2 \mathrm{M}$ solution. The value $1260 \pm 100$ is low compared to $\mathrm{MW}=$ $2500 \pm 1000$ reported by Kestigian et al., ${ }^{3}$ but in excellent agreement with a formula weight of 1183.5 for the octa-molybdate anion $\left[\mathrm{Mo}_{8} \mathrm{O}_{26}\right]^{4-}$. $\mathrm{MW}=660$ at $\mathrm{pH} 5.5$ indicates that at this $\mathrm{pH}$ and concentration, significant amounts of both the simple molybdate $\left(\mathrm{MoO}_{4}\right)^{2-}$ and the heptamolybdate $\left(\mathrm{Mo}_{7} \mathrm{O}_{24}\right)^{6-}$ exist in equilibrium. If we 
Table 1. Scattering results of molybdates and tungstates

\begin{tabular}{|c|c|c|c|c|c|c|}
\hline \multirow[t]{2}{*}{ Sample } & \multirow{2}{*}{$\begin{array}{l}\text { Conc. } \\
\text { wt. } z\end{array}$} & \multirow[t]{2}{*}{ pH } & \multirow{2}{*}{$\frac{X \text {-Ray }}{\operatorname{Rg}(A)}$} & \multicolumn{3}{|c|}{ Laser } \\
\hline & & & & Apparent MTr & $\operatorname{sh}(A)$ & $\begin{array}{l}\text { D1ff, Coeff. } \\
\left(\mathrm{x} 10^{6} \mathrm{~cm}^{2} / \mathrm{sec} \text { ) }\right.\end{array}$ \\
\hline \multirow{3}{*}{$\begin{array}{l}\text { Ammonium } \\
\text { Molybdate }\end{array}$} & 5 & 2.5 & 4.71 & $1260 \pm 100$ & 7.3205 & 3.1266 \\
\hline & 5 & 5.4 & 4.15 & $660 \pm 100$ & 5.3376 & 4.2881 \\
\hline & 12.5 & 9.0 & 2.95 & $470 \pm 100$ & - & - \\
\hline \multirow{3}{*}{$\begin{array}{l}\text { Sodium } \\
\text { Tungstate }\end{array}$} & 2.5 & 2.4 & 6.03 & $2760 \pm 100$ & 13.063 & 1.8757 \\
\hline & 2.5 & 5.5 & 4.36 & $660 \pm 100$ & 6.9732 & 3.5138 \\
\hline & 2.5 & 9.2 & 3.33 & $220 \pm 100$ & - & - \\
\hline
\end{tabular}

assume simple and heptamolybdate are the only anions present, a rough estimate based on the weight average molecular weight of 660 indicates that about $30 \%$ is in the hepta form, in good agreement with the Raman results discussed later. We also followed the change in the apparent molecular weight of polymeric species as a function of $\mathrm{pH}$. The results are shown in Fig. 1 for $0.1 \mathrm{M}$ solution. Starting from a $\mathrm{pH}$ of 2.4 , the $\mathrm{pH}$ of the solution in a light scattering cell was slowly lowered by dropwise addition of $2 \mathrm{M}$ or $10 \mathrm{M} \mathrm{HCl}$. The apparent molecular weight as computed from the intensity of the scattered light started at $\mathrm{MW}=350, \mathrm{pH}=2.4$ and increased to a maximum of 5200 at a pH of 1.1 ; it then decreased to a local minimum of $\mathrm{MW}=\mathbf{8 0 0}$ around the isoelectric point $(\mathrm{pH}=0.9)$. The apparent $\mathrm{MW}$ continued increasing with further lowering of the $\mathrm{pH}$ reaching $\mathrm{MW}=2500$ at $\mathrm{pH}=0.80$. We should note that all the changes were very rapid; even the dramatic increase in $\mathrm{MW}$ observed when going from a $\mathrm{pH}$ of 2.5-1.10 occurred over a period of three minutes. The molecular weight of the $\mathrm{pH} 2.5$ species is lower than the corresponding value obtained with a $0.2 \mathrm{M}$ solution by a factor of about three, indicating significant concentration dependence.

For the tungstate solutions, we find that $\mathrm{MW}=220 \pm 50,660 \pm 100,2760 \pm 100$ at $\mathrm{pH}$ $9.2,5.5$ and 2.4 respectively. $\mathrm{MW}=220 \pm 50$ is in very good agreement with the formula weight of the simple tungstate anion $\mathrm{WO}_{4}{ }^{2-}, \mathrm{MW}=247.8$. $\mathrm{MW}=660$ at $\mathrm{pH} 5.5$ indicates an equilibrium between the simple anion and the polymeric species. $\mathrm{MW}=2760 \pm 100$ at $\mathrm{pH}$ of 2.4 is in very good agreement with the formula weights of $\left[\mathrm{W}_{12} \mathrm{O}_{36}(\mathrm{OH})_{10}\right]^{10-}, \mathrm{FW}=2952$ of paratungstate- $\mathrm{B}$ and $\left[\mathrm{W}_{12} \mathrm{O}_{38}(\mathrm{OH})_{2}\right]^{6-}, \quad F W=2848$ of metatungstate. However, under the conditions of our experiments, the most likely species is either the paratungstate-B species or polytungstate- $Y$ species because our samples were relatively fresh.

In order to study the time dependent kinetics of the transition from paratungstate-A to paratungstate-B to $\Psi$-metatungstate, we first prepared a $0.07 \mathrm{M}$ sodium tungstate solution, acidified it to a pH of 5.0 and then heated it to $80^{\circ} \mathrm{C}$. The changes in the molecular weight were followed by measuring the intensity of the scattered light as a function of time. Figure 2 shows the results of our measurements. The starting point on the time axis corresponds to $1 \mathrm{hr}$ after the preparation of the sample because of the time consumed by the centrifugation of the sample to remove dust. At the start, there is already a small amount of paratungstate- $B$ as evidenced by the molecular weight of $M W=1800$. In a period of $6 \mathrm{hr}$, the measured molecular weight more than doubles and reaches a value of $\mathrm{MW}=4500$.

Also shown in Table 1 are the radii of gyration values determined from the angular dependence of the scattered X-ray intensity. Since these values are at the lower end of the measurable values by SAXS, their accuracy is low $( \pm 0.5 \mathrm{~A})$; however, they parallel changes in the molecular weight measurements. The hydrodynamic radii of the isopoly species are larger for the tungstates than the molybdates, in agreement with the molecular weight measurements.

It is interesting to note that if we use our values of the molecular weight and the diffusion coefficient to test Riecke's Law $D \sqrt{M}=$ constant, we find that the law seems to be holding: [pH 5.4] $\left(3.13 \times 10^{-6}\right) \sqrt{1260}=1.11 \times$ $10^{-4} \simeq\left(4.29 \times 10^{-6}\right) \sqrt{660}[\mathrm{pH} \mathrm{2.5}]=1.10 \times 10^{-4}$ for the isopolymolybdates and [pH 2.4] (1.88 $\times$ $\left.10^{-6}\right) \sqrt{2760}=9.88 \times 10^{-5} \simeq\left(3.51 \times 10^{-6}\right) \sqrt{660}$ [at $\mathrm{pH}$ 5.5] $=9.02 \times 10^{-5}$ for the tungstates. 


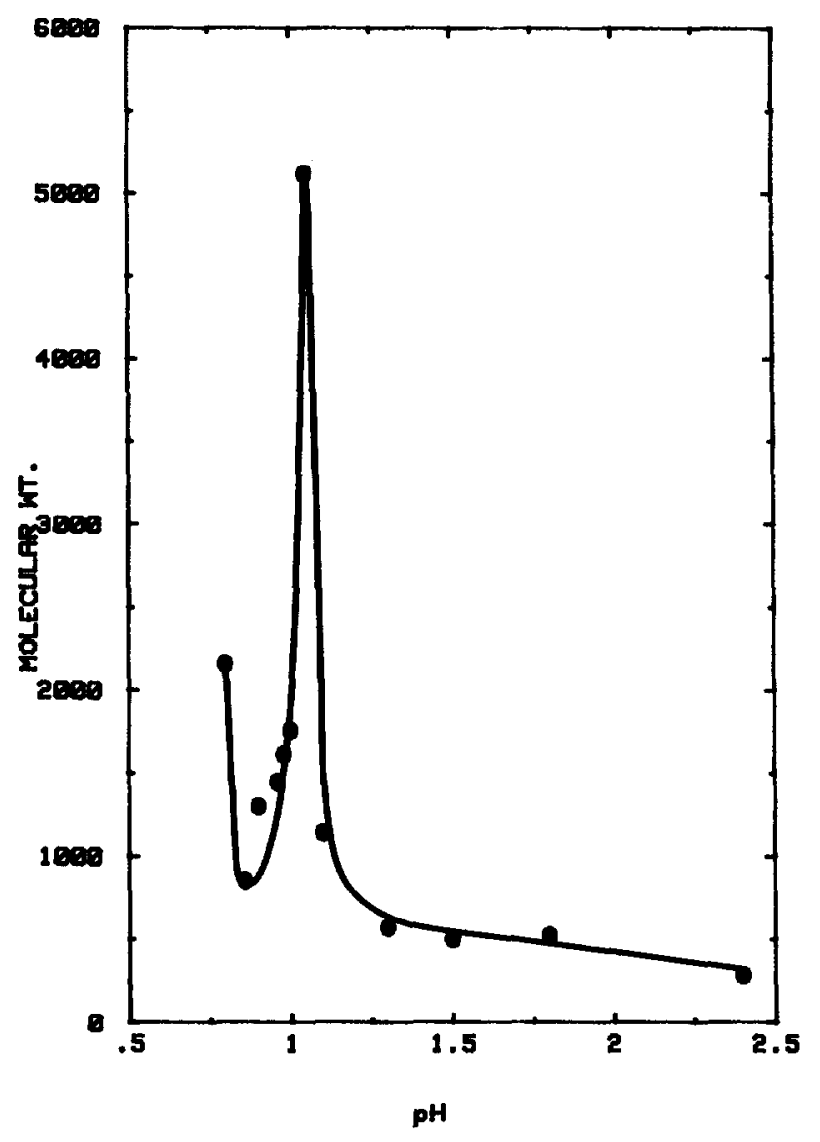

Fig. 1. Apparent molecular weights of the polymeric species as a function of $\mathrm{pH}$ for $0.1 \mathrm{M}$ ammonium heptamolybdate solution.

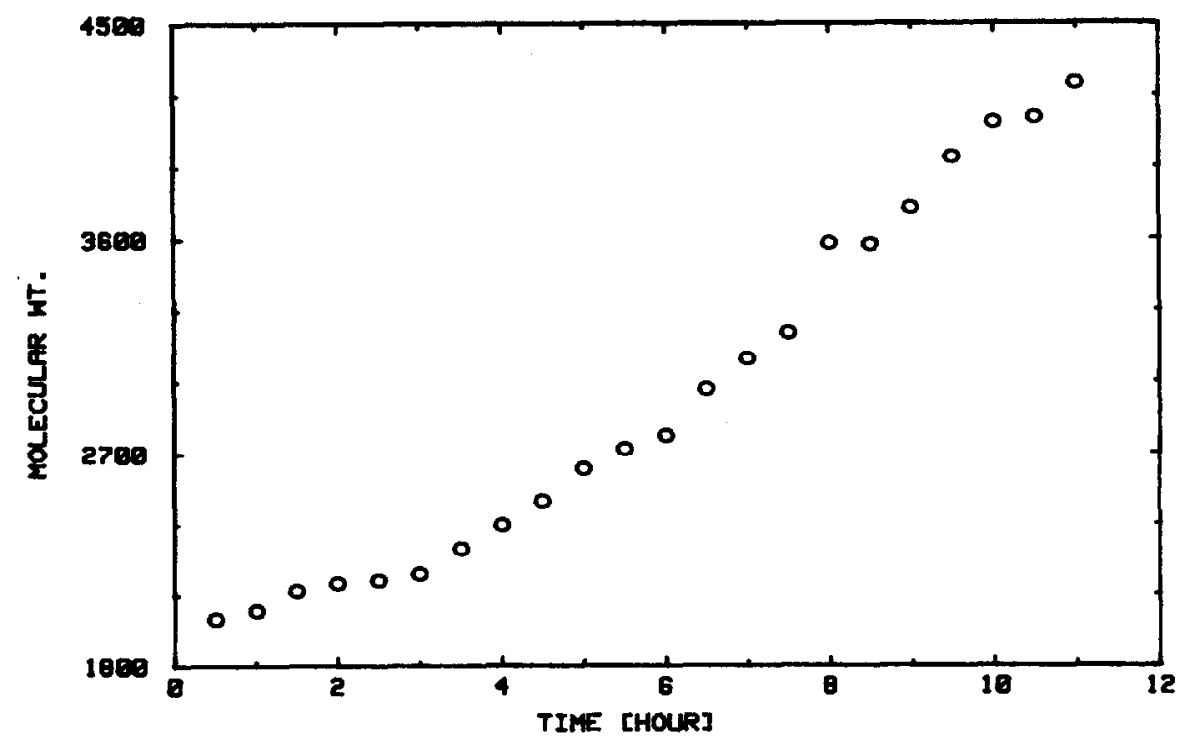

Fig. 2. Dynamic study of molecular weight of $0.07 \mathrm{M}$ sodium tungstate solution as a function of time at $80 \mathrm{C}$. The molecular weights obtained show the aggregation behaviour of tungstates with respect to time as Y-Polytungstate $\rightarrow$ Paratungstate-A $\rightarrow$ Paratungstate-B $\rightarrow \Psi$-Metatungstate. 


\section{(b) Raman spectroscopy}

(1) Raman spectra of the isomolybdates in solution. Raman spectra of isopolymolybdates were obtained as a function of $\mathrm{pH}$ and concentration. Figure 3 shows the $\mathrm{pH}$ dependence for $5 \%$ by weight of ammonium paramolybdate solution in the wavenumber range of 750 to $1000 \mathrm{~cm}^{-1}$. We see that at $\mathrm{pH} 9$ there are only two peaks: a sharp peak at $896 \mathrm{~cm}^{-1}$ and a broader peak at $854 \mathrm{~cm}^{-1}$. These are due to the $\mathrm{Mo}=0$ stretch. Upon acidification to a $\mathrm{pH}$ of 6.6 , both of the peaks decrease in intensity but a new strong peak at $939 \mathrm{~cm}^{-1}$ appears. This new peak is due to the formation of the heptamolybdate species in solution, which as seen from the Raman spectra exists in equilibrium with the $\left(\mathrm{MoO}_{4}\right)^{2-}$ anion. The fact that there is a sudden shift is proof that there are no appreciable intermediates between the simple and the heptamolybdate anions. At pH 5.4, the heptamolybdate series is the primary species but there is still a significant concentration of $\left(\mathrm{MoO}_{4}\right)^{2-}$ anion present. Further acidification to pH 2.2 leads to the appearance of two new peaks (one at $973 \mathrm{~cm}^{-1}$ and one at $844 \mathrm{~cm}^{-1}$ ), and the shifting of the two major $\mathrm{Mo}=\mathrm{O}$ stretch peaks to 958 and $913 \mathrm{~cm}^{-1}$. This is the first investigation in which the 973 and $844 \mathrm{~cm}^{-1}$ bands have been observed. At this $\mathrm{pH}$ and concentration ( $0.2 \mathrm{M}$ ) we expect the dominant isopoly species to be the octamolybdate anion $\left(\mathrm{Mo}_{8} \mathrm{O}_{26}\right)^{4-}$. It is possible that the new peaks are due to the formation of the more highly aggregated species such as the $\mathrm{Mo}_{36} \mathrm{O}_{112}{ }^{8-}$ anion. The time between the preparation of the sample and obtaining the Raman spectrum was less than half an hour, thus there should not be significant amounts of slow-forming aggregates. At

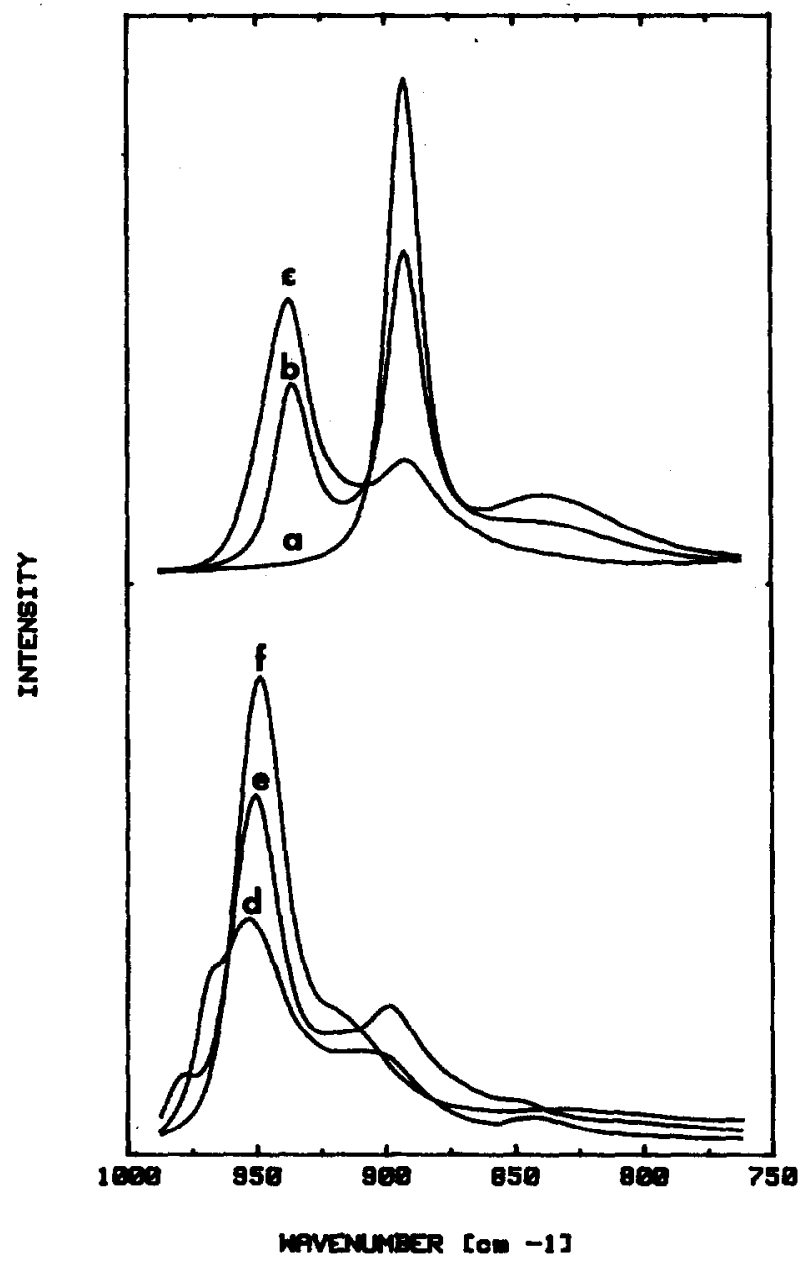

Fig. 3. Raman spectra of $0.2 \mathrm{M}$ AHM solution in high wavenumber region, as a function of $\mathrm{pH}$; (a) $\mathrm{pH} 9$, (b) $\mathrm{pH} 6.6$, (c) $\mathrm{pH} \mathrm{5.4,} \mathrm{(d)} \mathrm{pH} 2.2$, (e) $\mathrm{pH} 0.95$, (f) $\mathrm{pH} 0.3$. The sudden shift of the $896 \mathrm{~cm}^{-1}$ peak to the $939 \mathrm{~cm}^{-1}$ peak shows that there are no appreciable intermediates between the simple and the heptamolybdate anions. 
$\mathrm{pH} 0.95$, just above the isoelectric point of molybdic acid, there are still four peaks: the two major peaks at 954 and $911 \mathrm{~cm}^{-1}$ and the peaks at 835 and $982 \mathrm{~cm}^{-1}$. The final set of spectra at $\mathrm{pH}=0.3$ was taken with a lower concentration $(0.1 \mathrm{M})$ in order to prevent any precipitate formation. The spectrum of the $\mathrm{pH} 0.3$ sample is significantly different than the others. At pH 0.3, the high frequency band at $982 \mathrm{~cm}^{-1}$ completely disappears. Instead, the $953 \mathrm{~cm}^{-1}$ band is sharp and strong and a second peak at $933 \mathrm{~cm}^{-1}$ is observed. There is also a weak and broad third peak at $827 \mathrm{~cm}^{-1}$. All the wavenumbers given above were obtained after curve fitting the $\mathrm{M}=0$ stretch region with a sum of Gaussian bands.

The Raman spectra for pH's of 6.6, 2.2 and 0.95 show two weak and broad peaks between 400 and $600 \mathrm{~cm}^{-1}$. At $\mathrm{pH} 0.3$, there is only single asymmetric peak at $450 \mathrm{~cm}^{-1}$.

Figure 4 shows the Raman bands in the frequency range of $150-500 \mathrm{~cm}^{-1}$. A single strong peak at $318 \mathrm{~cm}^{-1}$ is observed for $\mathrm{pH} 9$ solutions. At $\mathrm{pH} 6.6$, two strong peaks at 318 and $208 \mathrm{~cm}^{-1}$ are observed; the stronger of the two is the
$318 \mathrm{~cm}^{-1}$. As the $\mathrm{pH}$ is lowered to 2.2 , the intensity of the $318 \mathrm{~cm}^{-1}$ band decreases and its position shifts to $363 \mathrm{~cm}^{-1}$. The intensity and position of the $208 \mathrm{~cm}^{-1}$ band stays constant but the frequency is shifted to $200 \mathrm{~cm}^{-1}$. Further acidification to $\mathrm{pH} 0.95$ shifts the $208-225 \mathrm{~cm}^{-1}$ and the peak structure indicates a possible splitting. At $\mathbf{p H ~} 0.3$, the 363 and $210 \mathrm{~cm}^{-1}$ peaks are still present and a third weak band at $300 \mathrm{~cm}^{-1}$ appears.

We also obtained the Raman spectra as a function of concentration at a $\mathrm{pH}$ of 5 for $\mathbf{0 . 2 , 0 . 0 4}$ and 0.008 molar molybdate solutions. The only significant change was the appearance of the $844 \mathrm{~cm}^{-1}$ band at the lower concentrations. The relative ratio of the $896 \mathrm{~cm}^{-1}$ to the $939-1$ bands also increased by about $10-15 \%$ with decreasing concentration.

(2) Raman spectra of the isopolytungstates in solution. Raman spectra of the tungstate solutions were obtained as a function of time, $\mathrm{pH}$ and concentration in order to elucidate the complex equilibrium processes present in isopolytungstate solutions. We followed the changes occurring in the solution by taking the spectra at $t=0, t=1$

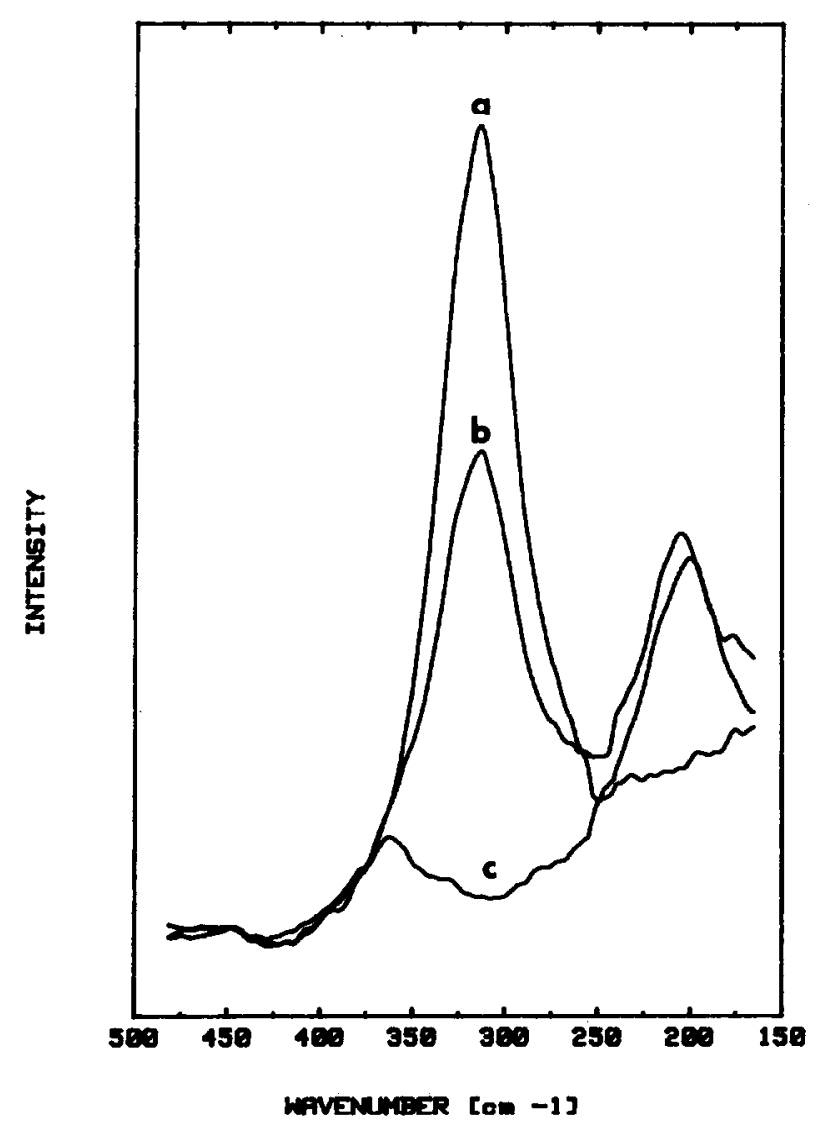

Fig. 4. Raman spectra of $0.2 \mathrm{M}$ AHM solution in low wavenumber region as a function of $\mathrm{pH}$; (a) pH 9, (b) pH 6.6, (c) pH 2.2. 
day and $t=6$ days. Figure 5 shows the Raman spectra of a $0.1 \mathrm{M}$ solution (pH 7.3) taken at $t=0$ and $t=6$ days. We see that there is a significant difference between the two spectra. After equilibration, the ratio of the $960-931 \mathrm{~cm}^{-1}$ peak has decreased. This decrease is accompanied by a slight broadening and upshift of the $931 \mathrm{~cm}^{-1}$ peak. The spectrum obtained after 1 day of aging is essentially the same. Time dependent changes were observed for the other solutions with different pH's. All the other Raman spectra shown in Fig. 6 were obtained after the samples had aged for 6 days. At pH 9, there is a sharp peak at $930 \mathrm{~cm}^{-1}$ (W=O stretch) and a broad peak at $834 \mathrm{~cm}^{-1}$ (W-O-W asymmetric stretch) characteristic of the monomeric $\mathrm{WO}_{4}{ }^{2-}$ anion. As the $\mathrm{pH}$ is lowered to 7.3, aggregation starts and two more peaks appear at 960 and $927 \mathrm{~cm}^{-1}$. These are due to the polymeric tungstate species in solution (most likely the paratungstate-B anion). In order to make more quantitative measurements we assumed that the scattering cross sections of all the Raman peaks in the $\mathrm{W}=\mathrm{O}$ stretch region remained the same (according to our measurements this assumption holds to within $10 \%$ ) and performed Gaussian deconvolution of the complex peaks. Judging from the results of Gaussian curve deconvolution, at $\mathbf{p H}$ $7.3,16 \%$ of the tungstate is in polymeric form. We should note that around this $\mathrm{pH}$ the relative ratios of the monomeric and polymeric species are very $\mathrm{pH}$ sensitive. As the $\mathrm{pH}$ is decreased to 4.9 , the intensity of the $960 \mathrm{~cm}^{-1}$ band increases at the expense of the $930 \mathrm{~cm}^{-1}$ band and curve deconvolution tells us that $80 \%$ of the tungstate is in the polymeric form. The fact that the frequency of the
$W=O$ band at $960 \mathrm{~cm}^{-1}$ has not shifted to higher frequencies indicates that the polymeric species present at $\mathrm{pH} 4.9$ are identical to those of $\mathrm{pH} 7.3$ (paratungstate-B). The $\mathrm{W}-\mathrm{O}-\mathrm{W}$ asymmetric stretching frequency for the polymeric species is shifted to directly under the $\mathrm{W}=\mathrm{O}$ stretching peak of the monomeric species at $930 \mathrm{~cm}^{-1}$. Further decrease of the $\mathrm{pH}$ to 3 results in a small shift of $5 \mathrm{~cm}^{-1}$ to $965 \mathrm{~cm}^{-1}$ for the $\mathrm{W}=\mathrm{O}$ vibration; the other peaks are at 933 and $894 \mathrm{~cm}^{-1}$, respectively. The width of the $\mathrm{W}=\mathrm{O}$ stretching peak increases with decreasing $\mathrm{pH}$ from $8 \mathrm{~cm}^{-1}$ at $\mathrm{pH} 9$ to $13 \mathrm{~cm}^{-1}$ at $\mathrm{pH}$ 3.0. Further acidification of the solution results in the precipitation of tungstic acid at a $\mathrm{pH}$ of 2.0. By decreasing the solution concentration we were able to get Raman spectra of solutions with $\mathrm{pH}$ 's as low as 1.7. At a pH of 2.2, strong peaks at $990 \mathrm{~cm}^{-1}, 975 \mathrm{~cm}^{-1}, 890 \mathrm{~cm}^{-1}$ and $838 \mathrm{~cm}^{-1}$ were observed.

Figure 7 shows the tungstate solution spectra at $\mathrm{pH}=6.6$ for $0.24,0.06$ and $0.015 \mathrm{M}$ solutions. For all three concentrations, there are three peaks: 960 , 930 and $895 \mathrm{~cm}^{-1}$. However, the relative intensities change drastically. The relative ratio of the $930 \mathrm{~cm}^{-1}$ peak (due to the simple anion $\left(\mathrm{WO}_{4}{ }^{2-}\right)$ to $960 \mathrm{~cm}^{-1}$ (due to the polymeric species A, B and $Y$ polytungstates) decreases with increasing concentration, and changes by almost a factor of twenty. The low frequency Raman peaks for the tungstate solutions are given in Table 2.

\section{DISCUSSION}

\section{(a) Light and $X$-ray scattering results}

The apparent molecular weight measurements we obtained in this study are in good agreement

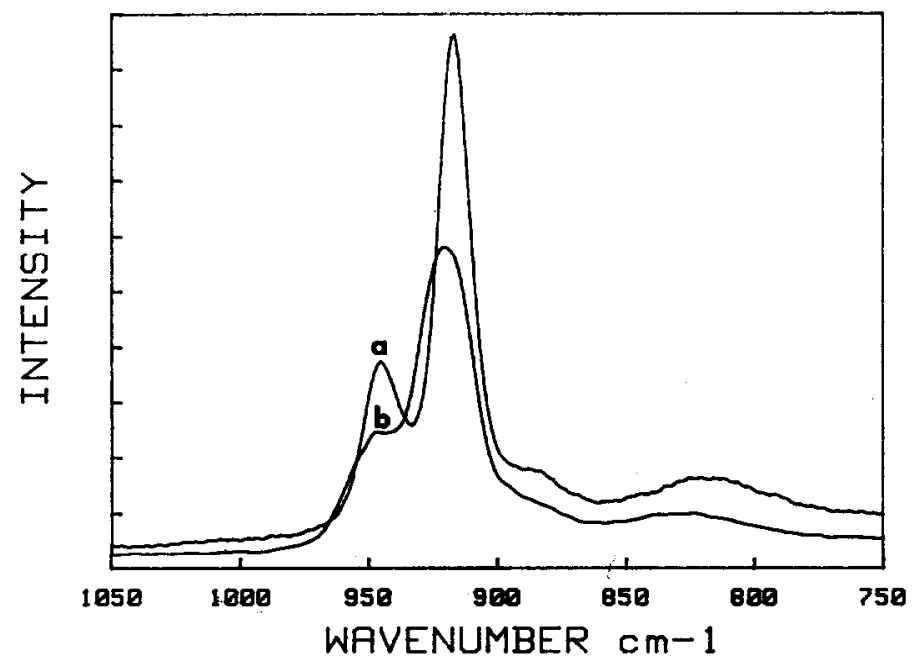

Fig. 5. Raman spectra of $0.1 \mathrm{M}$ sodium tungstate solution as a function of time; (a) $t=0$, (b) 6 days. After equilibration, the ratio of the $960-931 \mathrm{~cm}^{-1}$ peak has decreased. 


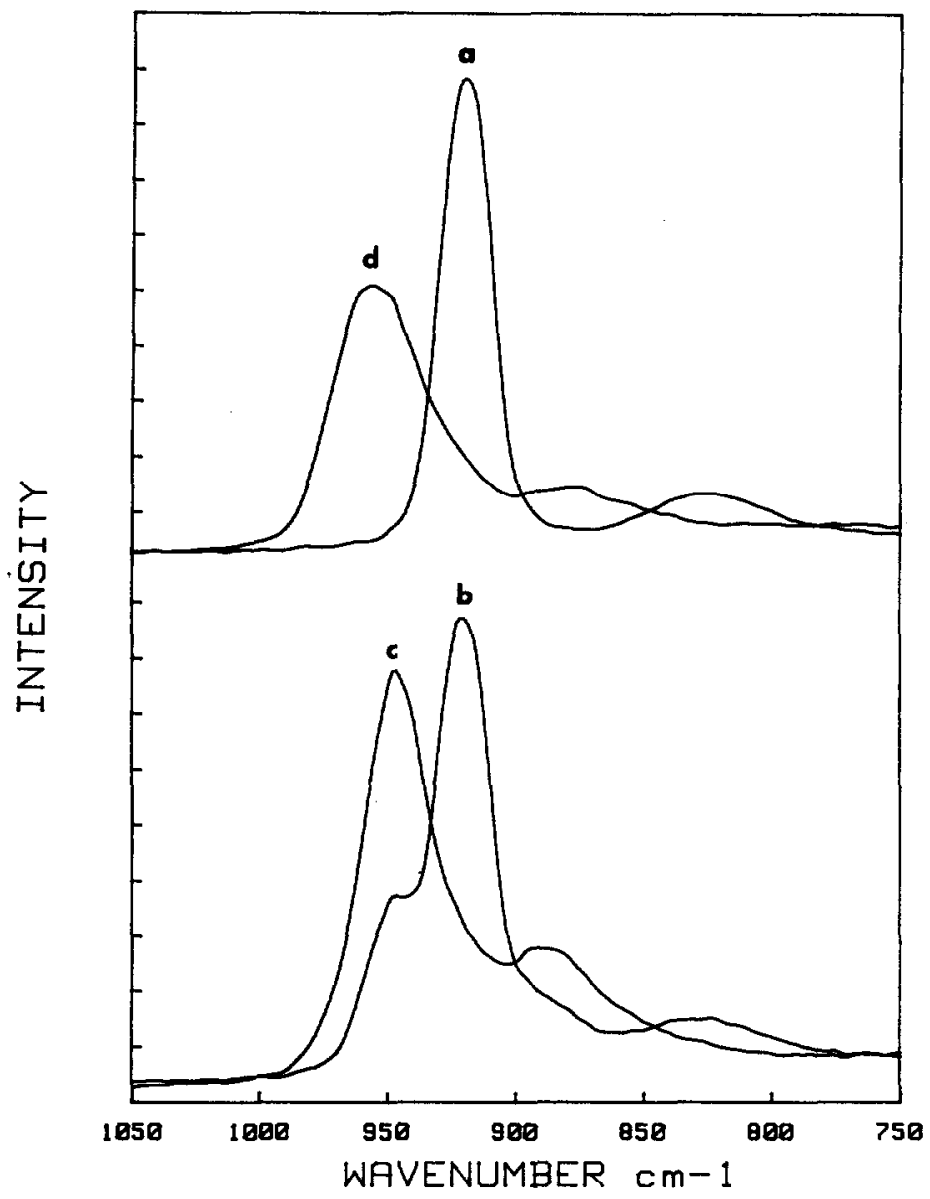

Fig. 6. Raman spectra of 6 day old $0.1 \mathrm{M}$ sodium tungstate solution as a function of $\mathrm{pH}$; (a) $\mathrm{pH}$ 9, (b) $\mathrm{pH} 7.3$, (c) $\mathrm{pH} 4.9$, (d) $\mathrm{pH} 3$.

with those determined by the sedimentation equilibrium method. ${ }^{2}$ Unfortunately, there is a significant concentration dependence and the resolution is not high enough to distinguish between the hepta- and octa-molybdate species in order to resolve the question whether or not octamolybdate is the dominant species at $\mathrm{pH}$ 's below 4.5. However, our light scattering measurements as a function of $\mathrm{pH}$ definitely show the rapid transition from the normal molybdate to hepta-(or octa-) molybdate, followed by the $\left(\mathrm{Mo}_{36} \mathrm{O}_{112}\right)^{8-}$ anion at a $\mathrm{pH}$ of 1.3 , reaching complete conversion at $\mathrm{pH}$ 1.10. These $\mathrm{pH}$ 's are low compared to Tytko and Glemser, ${ }^{2,15}$ but these authors did not give the concentration of their solutions. As a result, the comparisons in $\mathrm{pH}$ are only approximate. We have also observed a phenomenon that has not been observed before: a decrease in aggregation as $\mathrm{pH}$ is lowered from 1.1, reaching to a minimum molecular weight of 800 at a pH of 0.86 , and then rapidly increasing to $\mathrm{MW}=2200$ at a $\mathrm{pH}$ of 0.8 . This result indicates that below the isoelectric point of molybdic acid ( $\mathrm{pH} 0.9$ ), there is a different polymeric species (possibly positively charged) existing in very acidic solution. This finding is in good agreement with the Raman spectra which show a significant change at a $\mathrm{pH}$ of 0.95 . At the moment, we do not know the exact formula of this new species.

Our time-dependent studies of the changes in the molecular weight of the isopolymolybdates and isopolytungstates dramatically show the difference in the kinetics of aggregation between the two systems. For the isopolymolybdates, the aggregation is very fast. Upon acidification to $\mathrm{pH}$ of 1.0 , the molecular weight increased and reached a steady value of $\mathbf{M W}=\mathbf{5 2 0 0}$ in a few minutes. This indicates an almost complete conversion to $\left(\mathrm{Mo}_{36} \mathrm{O}_{112}\right)^{8-}$ anion, in agreement with the previous findings of Tytko et al. $^{15}$ In the isopolytungstates, the formation of paratungstate-A $(\mathrm{MW}=1490)$ is fast. At room temperature, aggregation to paratungstate- $B(M W=2952)$ also proceeds relatively fast. As seen in Fig. 2 , at $80^{\circ} \mathrm{C}$, further 


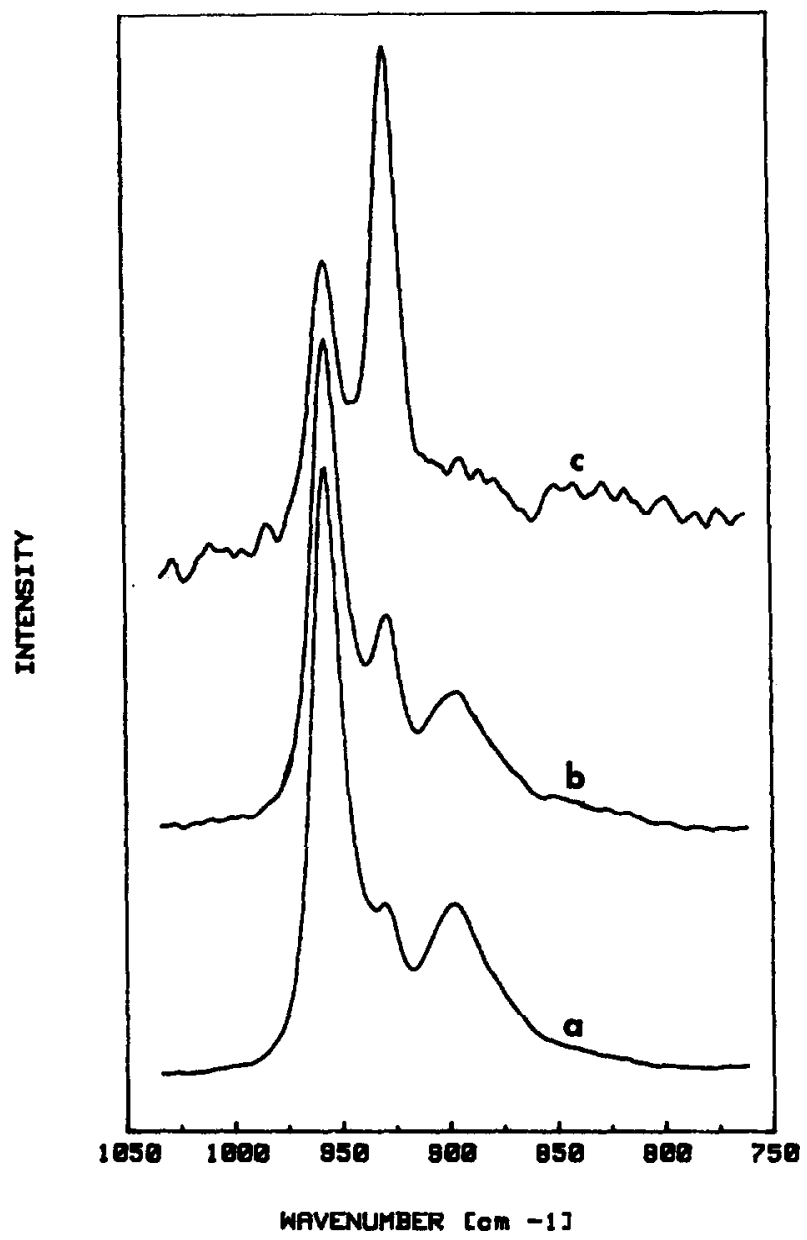

Fig. 7. Raman spectra of sodium tungstate solution at $\mathrm{pH} 6.6$ as a function of concentration; $a=0.24 \mathrm{M}, b=0.06 \mathrm{M}, c=0.015 \mathrm{M}$. The relative ratio of the $930 \mathrm{~cm}^{-1}$ peak (due to the simple anion $\mathrm{WO}_{4}^{2-}$ ) to $960 \mathrm{~cm}^{-1}$ peak (due to the polymeric species) decreases with increasing concentration.

aggregation of the present paratungstate- $B$ to $\Psi$-metatungstate is going on simultaneously with the aggregation of paratungstate $A$ to $B$. At the end of the $12 \mathrm{hr}$ period, the average molecular weight of the isopoly species is about 4500 , showing that the polymeric species are mostly $\boldsymbol{\Psi}$-metatungstate. After standing for another week, this solution contained large suspended crystallites of $2000-3000 \AA$ size, indicating that sodium- $\Psi$ metatungstate was precipitating out of solution even though there was no visible precipitate at the bottom.

Since our $\mathrm{Rh}$ and $\mathrm{Rg}$ values are the only data of their kind, it is not possible to make any comparisons with past work.

\section{(b) Raman results}

(1) Isopolymolybdates. Our measurements were made with very dilute solutions compared to pre- vious investigators. ${ }^{7,15,16}$ As a result, it is possible that some band frequencies are shifted slightly due to the concentration effect. The Raman spectrum of isopolymolybdates contains the following bands: around $900 \mathrm{~cm}^{-1}, \mathrm{MO}=0$ stretching; $840-750 \mathrm{~cm}^{-1}$, Mo-O-Mo asymmetric stretching, $600-400 \mathrm{~cm}^{-1}$, Mo-O-Mo symmetric stretching, $\mathrm{Mo}=\mathrm{O}$ bending at $350 \mathrm{~cm}^{-1}$, and Mo-O-Mo deformations at $200 \mathrm{~cm}^{-1}$. The $\mathrm{pH} 9$ spectrum has three strong bands at 896,854 and $318 \mathrm{~cm}^{-1}$. These frequencies are in very good agreement with the reported literature values. ${ }^{7,15,16}$ According to Tytko and Glesmer, ${ }^{2}$ the first stable polymeric species that is formed in appreciable quantities is the hepta $\left(\mathrm{Mo}_{7} \mathrm{O}_{24}\right)^{6-}$ molybdate. According to our measurements, this species is first detectable at a $\mathrm{pH}$ of 7.5 for $0.2 \mathrm{M}$ solutions. We also see no gradual shift in the frequencies of any of the $M O=0$ and Mo-O-Mo bands; rather, the changes in Raman 
Table 2. Low frequency Raman peaks of the $0.10 \mathrm{M}$ sodium solution as a function of $\mathrm{pH}$

\begin{tabular}{|c|c|c|}
\hline $\mathrm{pH}$ & Peak & $\underline{m}^{-1}$ \\
\hline \multirow[t]{4}{*}{9} & 330 & 8 \\
\hline & 475 & $w$ \\
\hline & 575 & $v$ \\
\hline & 480 & $v$ \\
\hline \multirow[t]{5}{*}{7.1} & 360 & 8 \\
\hline & 310 & 8 \\
\hline & 200 & 8 \\
\hline & 625 & $w$ \\
\hline & 450 & $\mathbf{w}$ \\
\hline \multirow[t]{3}{*}{4.7} & 360 & $w$ \\
\hline & 310 & $w$ \\
\hline & 200 & 8 \\
\hline
\end{tabular}

strong; $w$ = weak

spectrum are discrete. As soon as the $\mathrm{pH}$ is lowered to 7.0, we observe the presence of new bands at $939,450,208$ and $180 \mathrm{~cm}^{-1}$, along with the bands of $\left(\mathrm{MoO}_{4}\right)^{2-}$ given above. These new bands are due to the formation of the heptamolybdate anion as has been correctly assigned before. ${ }^{7}$ We have, however, for the first time demonstrated that the equilibrium between the simple and the heptamolybdate anions result in significant amounts of both over a wide $\mathrm{pH}$ range if we assume that the Raman cross sections are the same. Quantitative deconvolution of the Raman spectra show that even at pH 6.6, almost half of all molybdate is in hepta form. This transformation is complete at a $\mathrm{pH}$ of 4.5 for $0.2 \mathrm{M}$ solutions but for more dilute solutions the transformation is complete at lower pH values. All the Raman band frequencies for molybdates are in good agreement (within a few $\mathrm{cm}^{-1}$ ) with the previous measurements.

Perhaps the most significant controversy regarding isopolymolybdate solutions has been about the existence of the octamolybdate anion. Until 1976, it was assumed that lowering of the $\mathrm{pH}$ (or increasing the degree of protonation below $\mathrm{pH} 4.5$ ) resulted in the transformation of the heptamolybdate anion into the octamolybdate anion.
This conclusion was reached after comparing the structure of the crystalline octamolybdate Raman spectra to that of a concentrated solution of lithium or ammonium molybdate at a protonation ratio of $1.5^{7}$ Tytko and Schonfeld ${ }^{15}$ have argued strongly against this and have proposed a different aggregation scheme where the octamolybdate occurs in very small quantities and a new species $\left(\mathrm{Mo}_{36} \mathrm{O}_{112}\right)^{8-}$ is the main polymeric anion between pH 2.5 and pH $1.0(p=1.5-1.78)$. A close inspection of our Raman spectra does not show any bands at $700 \mathrm{~cm}^{-1}$, thus ruling out the polyoctamolybdate anion as a major component. ${ }^{15}$ These is, however, a distinct shift in the $\mathbf{M o}=0$ stretching frequency from 936 to $954 \mathrm{~cm}^{-1}$ as the $\mathrm{pH}$ goes from 5.4 to 2.2. Quantitative comparisons with the spectra given by Tytko and Schonfeld ${ }^{15}$ are impossible due to the lack of a table of peak frequencies in their paper. However, a qualitative comparison shows agreement with their $p=1.67$ (pH 2.0) spectra. Most of the peak frequencies we observe are very close to those reported by Anacker and Johnson, ${ }^{7}$ with the exception of the bands at $973 \mathrm{~cm}^{-1}$ and the ones at 450 and $600 \mathrm{~cm}^{-1}$. Qualitative agreement is also found with the Raman spectrum of tetrabutylammonium isooctamolybdate given by Fuchs and Brudgam, ${ }^{17}$ who had listed strong peaks at 957, 917, 857, 531, $481,367,307$ and $217 \mathrm{~cm}^{-1}$. These values, however, were obtained in an organic solvent and some of the bands may not be due to the octamolybdate anion. Our peak frequencies of $973,958,913,844$, 363 and $200 \mathrm{~cm}^{-1}$ for the $\mathrm{pH} 2.2$ solution are in quantitative agreement with the results of Griffith and Lesniak ${ }^{16}$ for crystalline ammonium octamolybdate and solution spectra for $\mathrm{pH} \mathrm{1.8.} \mathrm{Thus,}$ contrary to the arguments of Tytko, ${ }^{15}$ it is not possible to rule out the presence of significant amounts of octamolybdate anion on the basis of Raman and light scattering measurements alone. The Raman spectrum of $\mathrm{pH} 0.95$ solution is significantly different than that of $\mathrm{pH} 2.2$ solution. If we take the shift toward higher wavenumbers to be an indication of more aggregation, then the $982 \mathrm{~cm}^{-1}, \mathrm{Mo}=\mathrm{O}$ stretching band definitely shows the presence of aggregates much larger than the hepta and octamolybdate species. Qualitatively, our $\mathrm{pH} 0.95$ spectrum is in good agreement with the spectrum given by Tytko $^{15}$ for the $\left(\mathrm{Mo}_{36} \mathrm{O}_{112}\right)^{8-}$ anion. No quantitative comparisons are possible because of a lack of quantitative intensity and frequency information in Tytko's paper.

Since there are no other existing quantitative solution spectra below the isoelectric point, it is not possible to have a comparison of our $\mathrm{pH} 0.3$ spectrum. This spectrum is very different than 
those above the isoelectric point. If we again use the shift in the $M o=0$ stretching frequency as an indication of the degree of aggregation, we arrive at the conclusion that the species in solution has a degree of aggregation less than the 36 anion (in agreement with the light scattering measurements). At present, we do not have enough information to propose a formula for the isopoly species present in this strongly acidic solution.

(2) Isopolytungstates. The only other comprehensive Raman spectroscopy investigation of isopolytungstates is by Griffith. ${ }^{16}$ For $\mathrm{pH} 9$ solution, our peak frequencies fo 930,834 and $330 \mathrm{~cm}^{-1}$ are in exact agreement with their values. At a $\mathrm{pH}$ of 7.4 , they observe a new band at $908 \mathrm{~cm}^{-1}$ which is not present in our spectrum; however, we observed many more Raman bands due to the polymeric species in the low wavenumber region (as shown in Table 2). For pH 4.9 solution, our peak frequencies of $957,927,900,625,450,360,310$ and $200 \mathrm{~cm}^{-1}$ can be compared to Griffith's ${ }^{16} 980,966,941,902$, $650,460,420,348,200$ and $164 \mathrm{~cm}^{-1}$. The bands at 980,941 and $420 \mathrm{~cm}^{-1}$ that they observed are probably due to the polytungstate $A$ or $Y$ species which are present in large amounts only for a short period after the acidification of the solution. We also observe these bands when our solutions are fresh. A further possibility may be due to the tenfold difference in concentration $(1.0 \mathrm{M}$ versus our $0.1 \mathrm{M}$ solutions). Our spectra for the highly acidic solutions contain additional peaks at 838 and $875 \mathrm{~cm}^{-1}$ that they did not observe.

Acknowledgements-Financial support of this research by the National Science Foundation (DMR 81-00130 and CPE 79-20818) and ACS-PRF(13210-AC7-C) is gratefully acknowledged. All the spectrometers used were bought by equipment grants from the National Science Foundation and The Dreyfus Foundation.

\section{REFERENCES}

1. G. A. Tsigdinos and C. J. Hallada, Climax Molybdenum Co. Bulletin, Cdb-14, (1969).

2. K. H. Tytko and O. Glemser, Adv. Inorg. Chem. Radio Chem. 1976, 19, 239.

3. M. Kestigian, P. Colodny and R. S. Stein, J. Chem. Phys. 1958, 21, 952.

4. Y. Sasaki, I. Lindquist and L. G. Sillen, J. Inorg. Nucl. Chem. 1959, 9, 93.

5. O. Glemser, W. Holznagel, W. Holtje and E. Schwarzmann, Zeit Naturforsch 1965, 20b, 725.

6. A. Bartecki and D. Dembicka, J. Inorg. Nucl. Chem. 1967, 29, 2907.

7. J. Aveston, E. W. Anacker and J. S. Johnson, Inorg. Chem. 1964, 3, 735.

8. P. Souchay, Talanta 1965, 12, 1187.

9. C. Heitner-Wirguin and R. Cohen, J. Inorg. Nucl. Chem. 1964, 26, 161.

10. K. F. Jahr and J. Fuchs, Angew. Chem. Int. Edn. $1966,5,689$.

11. Y. Sasaki, Acta Chem. Scand. 1961, 15, 75.

12. J. Aveston, Inorg. Chem. 1964, 3, 981 .

13. G. Schwarzenbach, G. Geier, and J. Meier, J. Inorg. Nucl. Chem. 1958, 8, 302.

14. B. Chu, Laser Light Scattering. Academic Press, New York (1974).

15. K: H. Tytko and B. Schonfeld, $Z$ Naturforsch 1975 , 30b, 471.

16. W. P. Griffith and P. J. B. Lesniak, J. Chem. Soc. (A), 1969, 1066.

17. J. Fuchs and I. Brudgam, $Z$ Naturforsch 1977, 32b, 853. 